\title{
Dynamics and control of a novel buck-boost converter with low stresses on switches and diodes
}

\author{
Farzin Asadi ${ }^{1}$ *, Nurettin Abut ${ }^{2}$, Ismet Kandilli ${ }^{3}$ \\ ${ }^{1}$ Mechatronics Engineering Department, Kocaeli University, Kocaeli, Turkey \\ ${ }^{2}$ Electrical Engineering Department, Kocaeli University, Kocaeli, Turkey \\ ${ }^{3}$ Electronics and Automation Department, Kocaeli University, Kocaeli, Turkey
}

\section{A RT ICLE INFO}

\section{Article history:}

Received 17 January 2017

Received in revised form

16 May 2017

Accepted 17 June 2017

\section{Keywords:}

Buck-boost converter

Low stress

Non-minimum phase

State space averaging

\section{Introduction}

Voltage bucking/boosting is required in many applications such as car electronics (Luo and Ye, 2004; Zhu and Luo, 2007a, 2007b), fuel cell systems (Sahu and Rincón-Mora, 2004; Ren et al., 2008; Changchien et al., 2010; Liu et al., 2010) and digital devices like notebooks and cell phones. Some topologies are suggested for buck-boost converter using KY converter (Hwu \& Yau, 2008, 2009; Hwu et al., 2009a, 2009b). In Liao et al. (2012) a noninverting buck-boost converter for fuel cell systems was proposed. Ismail et al. (2008) puts two switched capacitor cell into the basic converter and obtained a series of DC-DC converters but input and output are not common grounded. Designing appropriate controller is an important aspect of power electronics converters. Without appropriate controller, output changes due to disturbances like: Output load's changes and input source's changes. Dynamic and control of a recently published buckboost converter Miao et al. (2016) studied in this paper. Converter in Miao et al. (2016) has the benefits such as voltage stresses on switches and diodes are low, high step down gain, input and output terminal share the same ground, and output voltage is positive.

\footnotetext{
* Corresponding Author.

Email Address: farzin.asadi@kocaeli.edu.tr (F. Asadi) https://doi.org/10.21833/ijaas.2017.08.021

2313-626X/C) 2017 The Authors. Published by IASE. This is an open access article under the CC BY-NC-ND license (http://creativecommons.org/licenses/by-nc-nd/4.0/)
}

Floatation of MOSFET's (i.e. MOSFET sources are not connected to ground) is the main disadvantage of this converter. It needs a more complex gate drive circuitry.

This paper is organized as follows: Operating principle and steady state analysis are presented in section 2. Converter's small signal model, Controller design and Simulink ${ }^{\circledR}$ simulations are discussed in section 3. Finally, the appropriate conclusion is drawn.

\section{Operating principles and steady state analysis}

Fig. 1 shows the converter proposed in Miao et al. (2016).

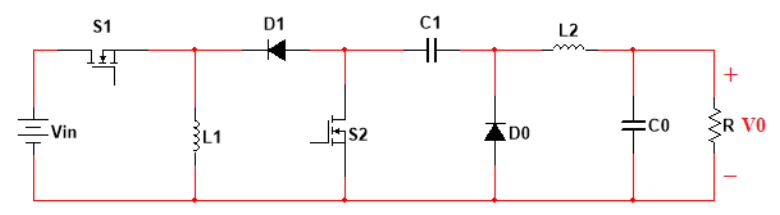

Fig. 1: Converter's structure

There are two possible operation modes when converter operates in CCM.

Mode 1) $N T_{s}<t<(N+D) T_{s}$

During this time interval, the power switches $\mathrm{S}_{1}$ and $S_{2}$ are conducted while the diodes $D_{1}$ and $D_{0}$ are reverse biased. Fig. 2 shows the equivalent circuit of this time interval: 


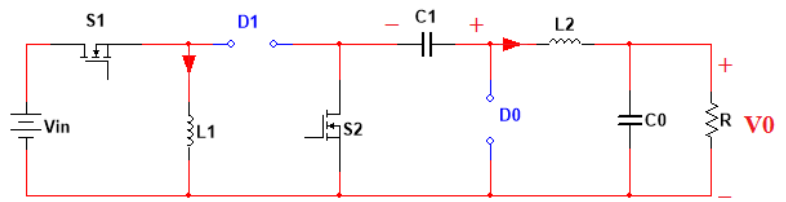

Fig. 2: Equivalent circuit of mode 1

Mode 2) $(N+D) T_{s}<t<(N+1) T_{S}$

During this time interval, diodes $\mathrm{D}_{0}$ and $\mathrm{D}_{1}$ are forward biased while switches $S_{1}$ and $S_{2}$ are turned off. Fig. 3 shows the equivalent circuit of this time interval:

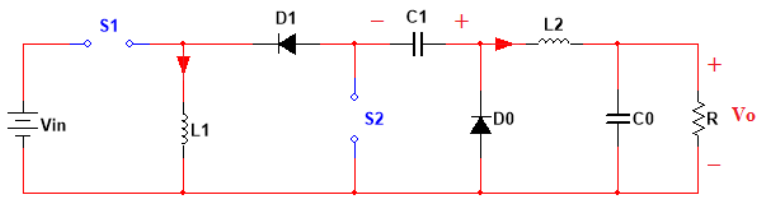

Fig. 3: Equivalent circuit of mode 2
Applying volt second balance (Mohan and Undeland, 2007) principle on the inductors $L_{1}$ and $L_{2}$ leads to (Eqs. 1 and 2):

$V_{c 1}=\frac{D}{1-D} V_{\text {in }}$

$M=\frac{V_{o}}{V_{\text {in }}}=\frac{D^{2}}{1-D}$

Converter step down the input voltage when $D<$ 0.618. Otherwise it steps up the input voltage. Voltage stresses on the power switches $\left(S_{1}\right.$ and $S_{2}$ ) and diodes $\left(D_{0}\right.$ and $\left.D_{1}\right)$ can be obtained as follows (Eqs. 3-6). A comparison is done in Table 1.

$V_{S 1}=\frac{1}{1-D} V_{i n}$
$V_{S 2}=\frac{D}{1-D} V_{i n}$
$V_{D 0}=\frac{D}{1-D} V_{i n}$
$V_{D 1}=V_{i n}$

Table 1: Comparison among converters

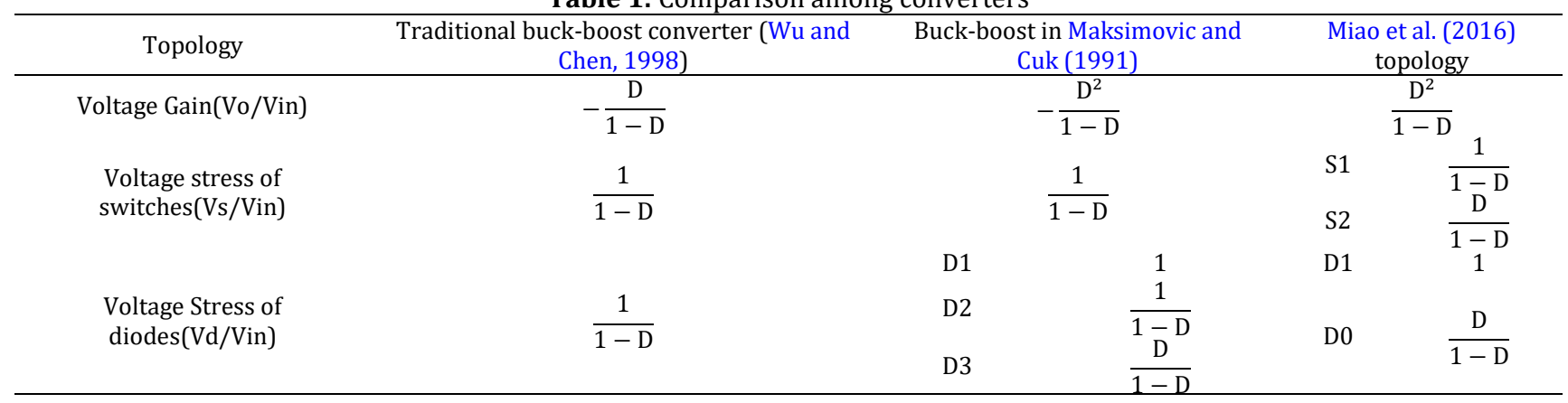

\section{Small signal modeling and controller design}

Modeling is the process of formulating a mathematical description of the system. Obtaining the mathematical model of system is the first step toward designing a controller in model base controller design techniques. Switching power converters are nonlinear variable structure systems. Various techniques can be found in literature to obtain a linear continuous Time Invariant (LTI) model of a DC-DC converter. The most well-known methods are: Current injected approach, circuit averaging and state space averaging (Middlebrook and Cuk, 1977; Kislovski et al., 1991; Mohan and
Undeland, 2007). Averaging and small signal linearization is key steps of these methods.

State Space Averaging (SSA) described in Middlebrook and Cuk (1977) is appropriate to describe converters that work in CCM while is less suitable for converters work in DCM. The current injected method (Kislovski et al., 1991; Mohan and Undeland, 2003) can do the job of modeling in either CCM or DCM. Circuit averaging gained a lot of attention recently due to its generality (Hren and Slibar, 2005). This paper uses, SSA to obtain the converter's model. Fig. 4 shows the equivalent circuit for mode $1\left(N T_{s}<t<(N+D) T_{s}\right)$.

Corresponding differential equations are established as (Eq. 7):
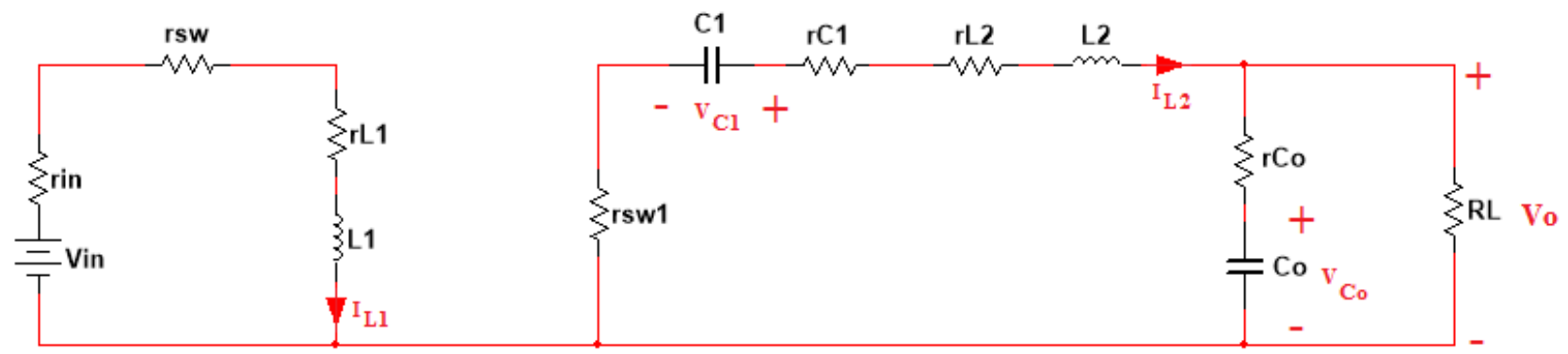

Fig. 4: Equivalent circuit of mode 1 in presence of circuit's non idealities 


$$
\left\{\begin{array}{l}
\frac{d\left(i_{L 1}\right)}{d t}=-\frac{\left(r_{i n}+r_{S w 1}+r_{L 1}\right)}{L_{1}} i_{L 1}+\frac{1}{L_{1}} V_{i n} \\
\frac{d\left(i_{L 2}\right)}{d t}=-\frac{1}{L_{2}}\left(r_{S W 2}+r_{C 1}+r_{L 2}+\frac{r_{C O}}{\alpha}\right) i_{L 2}+\frac{1}{L_{2}} v_{C 1}-\frac{1}{L_{2}}\left(1-\frac{r_{C o}}{R \times \alpha}\right) v_{C o} \\
\frac{d\left(v_{C 1}\right)}{d t}=-\frac{1}{C_{1}} i_{L 2} \\
\frac{d\left(v_{C 2}\right)}{d t}=\frac{1}{\alpha \times C_{o}} i_{L 2}-\frac{1}{R \times \alpha \times C_{o}} v_{C o}
\end{array}\right.
$$

where $\alpha=1+\frac{r_{C o}}{R}$. Fig. 5 shows the equivalent circuit for mode $2\left((N+D) T_{s}<t<(N+1) T_{s}\right)$. The equations for describing this mode can be derived as (Eq. 8):

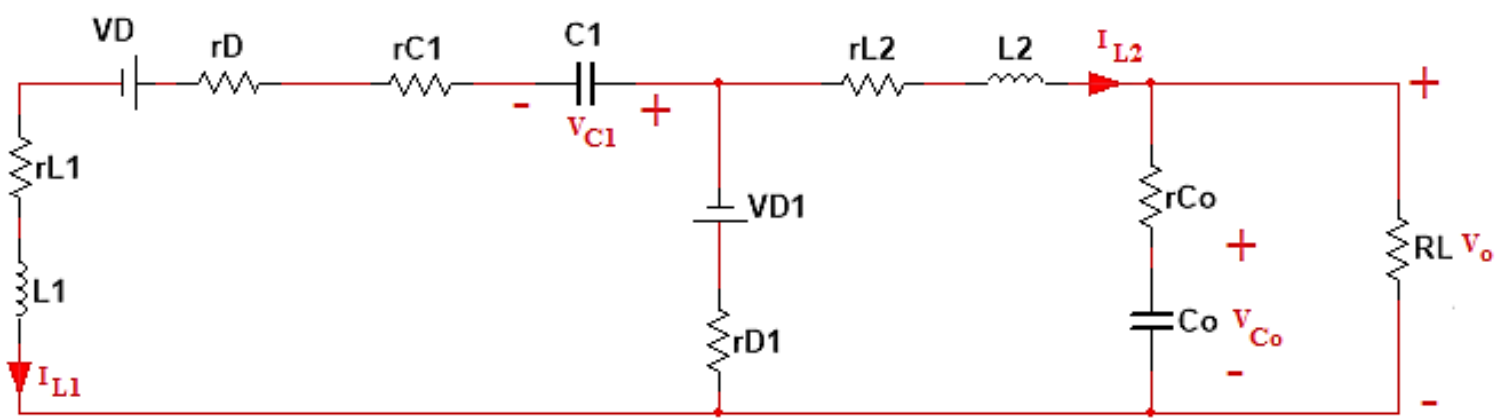

Fig. 5: Equivalent circuit of mode 1 in presence of circuit's non idealities

$$
\left\{\begin{array}{l}
\frac{d\left(i_{L 1}\right)}{d t}=-\frac{\left(r_{D 0}+r_{D 1}+r_{C 1}+r_{L 1}\right)}{L_{1}} i_{L 1}-\frac{r_{D 0}}{L_{1}} i_{L 2}-\frac{v_{C 1}}{L_{1}}-\frac{2}{L_{1}} v_{D} \\
\frac{d\left(i_{L 2}\right)}{d t}=-\frac{r_{D 0}}{L_{2}} i_{L 1}-\frac{1}{L_{2}}\left(r_{D 0}+r_{L 2}+\frac{r_{C O}}{\alpha}\right) i_{L 2}-\frac{1}{L_{2}}\left(1-\frac{r_{C o}}{R \times \alpha}\right) v_{C o}-\frac{1}{L_{2}} v_{D} \\
\frac{d\left(v_{C 1}\right)}{d t}=\frac{1}{C_{1}} i_{L 1} \\
\frac{d\left(v_{C 2}\right)}{d t}=\frac{1}{\alpha \times C_{o}} i_{L 2}-\frac{1}{R \times \alpha \times C_{o}} v_{C o}
\end{array}\right.
$$

Using pencil-and-paper analysis to extract converter's small signal transfer function is tedious, time consuming and error prone. MATLAB can be quite helpful for this purpose. Assume a converter with the following parameters:

Vin $=15 \mathrm{~V}, r_{\text {internal }}=0.01 \Omega, f=25 \mathrm{Khz}, D=0.75, L_{1}=3 \mathrm{mH}, r L_{1}=$ $30 \mathrm{~m} \Omega, L_{2}=1 \mathrm{mH}, r L_{2}=10 \mathrm{~m} \Omega C_{1}=20 \mu \mathrm{F}, r_{C 1}=5 \mathrm{~m} \Omega, C o=20$ $\mu F, r_{C O}=15 \mathrm{~m} \Omega, V_{D}=0.7, r_{D}=0.05 \Omega, r_{M O S F E T}=40 \mathrm{~m} \Omega, R_{L}=15 \Omega$.

With this values output voltage must be about 30 . Assume output load changes from $15 \Omega$ to $12 \Omega$ at $\mathrm{t}=25 \mathrm{~ms}$. Output of this scenario is shown in Fig. 6 .

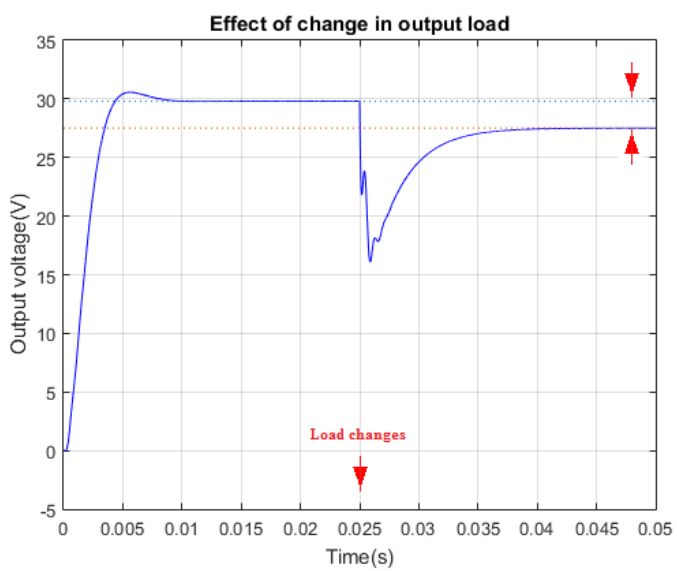

Fig. 6: Effect of output load change on output voltage

As shown in Fig. 6 output voltage is affected so a controller is required to keep output voltage constant despite of such disturbances. Applying SSA to Eqs. 7 and 8 leads to following transfer functions
(Eqs. 9, 10, and 11). Pole-zero diagram of these transfer functions are shown in Fig. 7, 8, and 9:

$$
\begin{aligned}
\frac{\tilde{v}_{o}(s)}{\tilde{d}(s)} & =\frac{2.11 \times 10^{9} s^{2}-1.521 \times 10^{13} s+1.077 \times 10^{16}}{s^{4}+3425 s^{3}+7.944 \times 10^{7} s^{2}+9.978 \times 10^{10} s+5.545 \times 10^{13}} \\
\frac{\tilde{t}_{L 1}(s)}{\tilde{d}(s)} & =\frac{1.935 \times 10^{4} s^{3}+9.942 \times 10^{7} s^{2}-1.763 \times 10^{12} s+3.96 \times 10^{15}}{s^{4}+3425 s^{3}+7.944 \times 10^{7} s^{2}+9.978 \times 10^{10} s+5.545 \times 10^{13}} \\
\frac{\tilde{t}_{L 2}(s)}{\tilde{d}(s)} & =\frac{4.222 \times 10^{4} s^{3}-1.636 \times 10^{8} s^{2}-7.987 \times 10^{11} s+7.178 \times 10^{14}}{s^{4}+3425 s^{3}+7.944 \times 10^{7} s^{2}+9.978 \times 10^{10} s+5.545 \times 10^{13}}
\end{aligned}
$$

As shown in the above figures, $\frac{\tilde{v}_{O}(s)}{\tilde{d}(s)}$ and $\frac{\tilde{l}_{L 2}(s)}{\tilde{d}(s)}$ are non-minimum phase, i.e. have zeros in Right Half Plane (RHP). Although control engineering has considerable progress over recent decades, most applications use PID controllers, because of their low price and simplicity. Generally speaking, using derivative term is not so common in power electronics converters control. Usually a $\mathrm{P}$ or PI controller is all that is required.

Assume zero steady state error is required. So, open loop transfer function must contain an integrator. Assume a simple I-type controller (Eq. 12):

$H_{\text {controller }}(s)=\frac{K_{i}}{s}$

Using Routh-Hurwitz table $0<K_{i}<2.36$ stabilize the close loop system. $K_{i}=0.40$ is selected to have no overshoot. Fig. 10 shows the Simulink diagram of the system. 


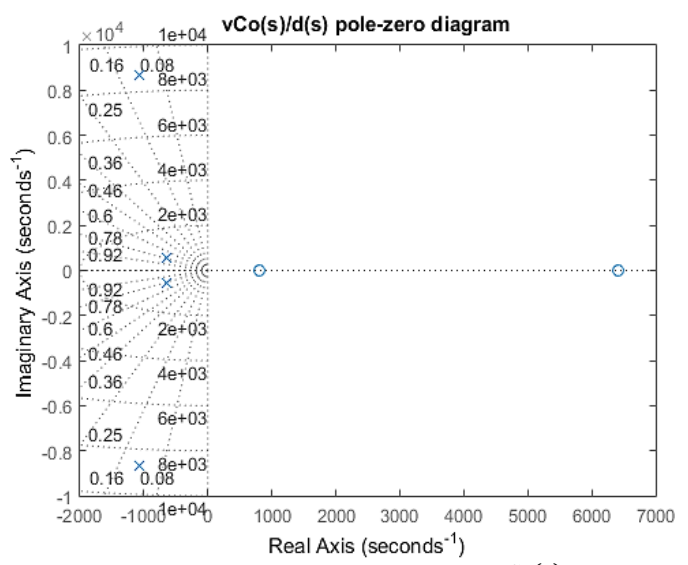

Fig. 7: Pole zero diagram of $\frac{\tilde{v}_{o}(s)}{\tilde{d}(s)}$

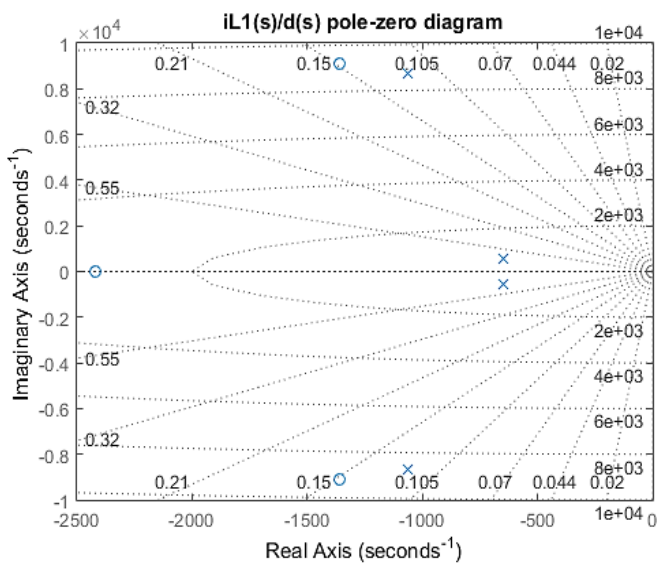

Fig. 8: Pole zero diagram of $\frac{\tilde{I}_{L 1}(s)}{\tilde{d}(s)}$

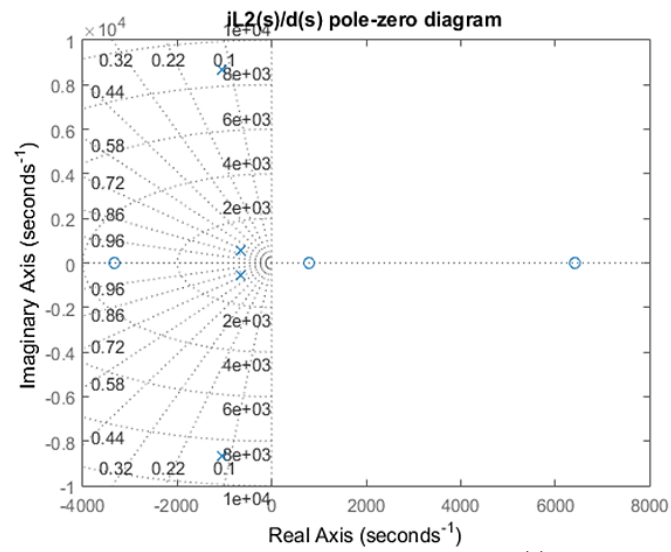

Fig. 9: Pole zero diagram of $\frac{\tilde{l}_{L 2}(s)}{\tilde{d}(s)}$

Testing the performance of close loop system is done with the aid of following scenario: Input voltage source changes from $15 \mathrm{~V}$ to $12 \mathrm{~V}$ at $\mathrm{t}=200 \mathrm{~ms}$, output load changes from $15 \Omega$ to $7.5 \Omega$ at $\mathrm{t}=300 \mathrm{~ms}$ and finally, control system reference signal changes form $20 \mathrm{~V}$ to $25 \mathrm{~V}$ at $\mathrm{t}=350 \mathrm{~ms}$. Table 2 summarize the aforementioned scenario. Simulation result is shown in Fig. 11. As shown in Fig. 11, controller keeps output voltage constant despite of disturbances.

Table 2: Test scenario

\begin{tabular}{ccccc} 
Parameter & Time & From & To & $\frac{\text { Initial - Final }}{$\cline { 4 - 4 }} \\
& & & Initial \\
\hline Input voltage & $200 \mathrm{~ms}$ & $15 \mathrm{~V}$ & $12 \mathrm{~V}$ & $-20 \%$ \\
Output load & $300 \mathrm{~ms}$ & $15 \Omega$ & $7.5 \Omega$ & $-50 \%$ \\
Reference voltage & $350 \mathrm{~ms}$ & $20 \mathrm{~V}$ & $25 \mathrm{~V}$ & $+25 \%$ \\
\hline
\end{tabular}

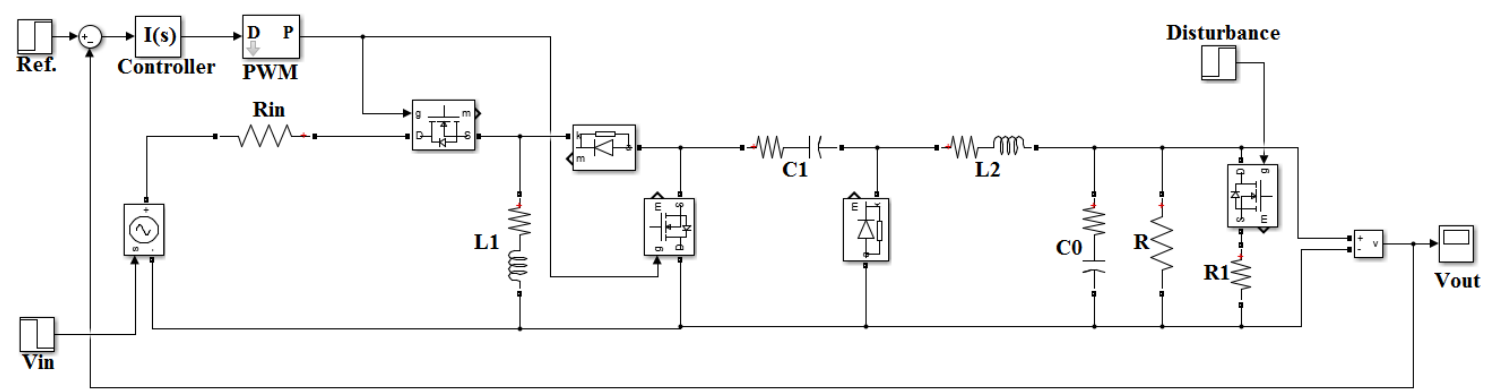

Fig. 10: Simulink diagram of system

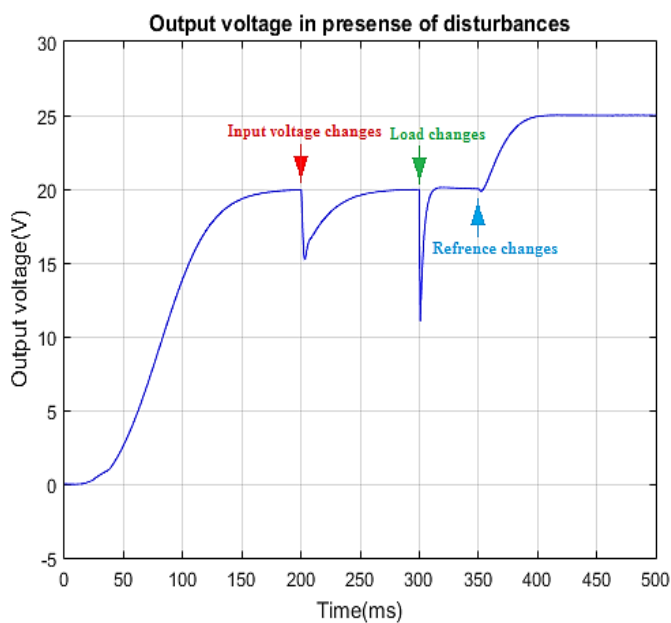

Fig. 11: Output voltage in presence of disturbances (Table 2's scenario)

\section{Conclusion}

Dynamics and control of a recently published buck-boost converter is studied in this paper. Studied converter has advantages like: Low voltage stresses on switches and diodes, high step down gain, positive output voltage and common ground between input and output. This paper shows studied converter has even one more advantage: its control can be done with a simple I-type controller. Proposed system can be used to drive DC motors.

\section{References}

Changchien SK, Liang TJ, Chen JF, and Yang LS (2010). Novel high step-up DC-DC converter for fuel cell energy conversion system. IEEE Transactions on Industrial Electronics, 57(6): 2007-2017. 
Hren A and Slibar P (2005). Full order dynamic model of SEPIC converter. In the IEEE International Conference on Industrial Electronics, IEEE. Palo Alto, USA: 2: 553-558. https://doi.org/10.1109/PESC.1977.7070802

Hwu KI and Yau YT (2008). A novel voltage-bucking/boosting converter: KY buck-boost converter. In the IEEE International Conference on Industrial Technology (ICIT'08), IEEE: 1-4. https://doi.org/10.1109/ICIT.2008.4608692

Hwu KI and Yau YT (2009). Two types of KY buck-boost converters. IEEE Transactions on Industrial Electronics, 56(8): 2970-2980.

Hwu KI, Chen YH, and Lin ZF (2009a). Negative-output KY buckboost converter. In the $4^{\text {th }}$ IEEE Conference on Industrial Electronics and Applications (ICIEA'09), IEEE, Xi'an, China: 3347-3350. https://doi.org/10.1109/ICIEA.2009.5138823

Hwu KI, Lin ZF, and Chen YH (2009b). A novel negative-output KY buck-boost converter. In International Conference on Power Electronics and Drive Systems (PEDS'09), IEEE: 1158-1162. https://doi.org/10.1109/PEDS.2009.5385717

Ismail, EH, Al-Saffar MA, Sabzali AJ, and Fardoun AA (2008). A family of single-switch PWM converters with high step-up conversion ratio. IEEE Transactions on Circuits and Systems I: Regular Papers, 55(4): 1159-1171.

Kislovski AS, Redl R, and Sokal NO (1991). Dynamic analysis of switching-mode DC/DC converters. Design Automation Inc., Lexington, USA.

Liao HK, Liang TJ, Yang LS, and Chen JF (2012). Non-inverting buck-boost converter with interleaved technique for fuel-cell system. IET Power Electronics, 5(8): 1379-1388.

Liu WS, Chen JF, Liang TJ, Lin RL, and Liu CH (2010). Analysis, design, and control of bidirectional cascoded configuration for a fuel cell hybrid power system. IEEE Transactions on Power Electronics, 25(6): 1565-1575.

Luo FL and Ye H (2004). Positive output multiple-lift push-pull switched-capacitor Luo-converters. IEEE Transactions on Industrial Electronics, 51(3): 594-602.
Maksimovic D and Cuk S (1991). Switching converters with wide DC conversion range. IEEE Transactions on Power Electronics, 6(1): 151-157.

Miao S, Wang F, and Ma X (2016). A novel buck-boost converter with low stresses on switches and diodes. In the IEEE $8^{\text {th }}$ International Power Electronics and Motion Control Conference, IEEE, Hefei, China: 3344-3347. https://doi.org/10.1109/IPEMC.2016.7512831

Middlebrook RD and Cuk S (1977). A general unified approach to modeling switching-converter power stages. International Journal of Electronics Theoretical and Experimental, 42(6): 521-550.

Mohan N and Undeland TM (2007). Power electronics: Converters, applications, and design. John Wiley \& Sons, New York, USA.

Ren X, Tang Z, Ruan X, Wei J, and Hua G (2008). Four switch buckboost converter for telecom DC-DC power supply applications. In the $23^{\text {rd }}$ Annual IEEE Applied Power Electronics Conference and Exposition (APEC'08), IEEE: 1527-1530. https://doi.org/10.1109/APEC.2008.4522927

Sahu B and Rincón-Mora GA (2004). A low voltage, dynamic, noninverting, synchronous buck-boost converter for portable applications. IEEE Transactions on Power Electronics, 19(2): 443-452.

Wu TF and Chen YK (1998). Modeling PWM DC/DC converters out of basic converter units. IEEE transactions on Power Electronics, 13(5): 870-881.

Zhu M \& Luo FL (2007a). Development of voltage lift technique on double-output transformerless DC-DC converter. In the $33^{\text {rd }}$ Annual Conference of Industrial Electronics Society (IECON'07), IEEE, Taipei, Taiwan: 1983-1988. https://doi.org/10.1109/IECON.2007.4460172

Zhu M and Luo FL (2007b). Implementing of developed voltage lift technique on SEPIC, Cuk and double-output DC-DC converters. In the $2^{\text {nd }}$ IEEE Conference on Industrial Electronics and Applications (ICIEA'07). IEEE, Harbin, China: 674-681. https://doi.org/10.1109/ICIEA.2007.4318492 